\title{
Analisis dan Rencana Pengembangan Jaringan Distribusi Air Bersih Unit Cabang Timur PDAM Kabupaten Klaten
}

\author{
Ana Tri Lestari dan Hariwiko Indarjanto \\ Jurusan Teknik Lingkungan, Fakultas Teknik Sipil dan Perencanaan, Institut Teknologi Sepuluh \\ Nopember (ITS) \\ Jl. Arief Rahman Hakim, Surabaya 60111 Indonesia \\ e-mail: hwcorp@yahoo.com
}

\begin{abstract}
Abstrak-Unit Cabang Timur Perusahaan Daerah Air Minum (PDAM) Kabupaten Klaten dibagi menjadi 3 unit pelayanan Ibu Kota Kecamatan (IKK) dan mempunyai tingkat pelayanan yang masih rendah pada tahun 2015, yaitu Unit IKK Ceper 17,6\%; Unit IKK Pedan 2,43\%; dan Unit IKK Cawas 31,26\% sehingga peningkatan persen pelayanan menjadi hal yang perlu dilakukan. Hal ini didukung dengan adanya penambahan debit produksi sebesar 50 liter/detik. Selain itu, jaringan distibusi belum dibentuk blok pelayanan sehingga sulit untuk mengontrol kehilangan air. Perencanaan ini dilakukan pembagian blok pelayanan menjadi 26 blok dan 5 tapping. Setelah itu dilakukan analisis kondisi eksiting. Hasil analisis kondisi eksisting menunjukkan kondisi hidrolika perpipaan kecuali kecepatan masih memenuhi kriteria, yaitu tekanan antara $(15,43-59,99) \mathrm{m}$, kecepatan $(0-0,91) \mathrm{m} /$ detik, unit headloss $(0-3,51) \mathrm{m} / \mathrm{km}$. Kemudian dilakukan pengembangan jaringan yang dibagi menjadi 2 tahap, dimana tahap 1 meningkatkan persen pelayanan, sedangkan tahap 2 menambah daerah pelayanan baru. Blok pelayanan setelah pengembangan menjadi 29 blok dan 5 titik tapping. Kemudian analisis rencana pengembangan dilakukan dan menunjukkan bahwa kondisi hidrolika pipa untuk tekanan di jaringan distribusi IKK Cawas bernilai negatif. Hal ini dikarenakan unit headloss yang terjadi pada pipa dari reservoir menuju titik tapping pertama IKK Cawas sebesar 5,78 $\mathrm{m} / \mathrm{km}$ dengan panjang pipa $14,35 \mathrm{~km}$ sehingga headloss sebesar 82,94 m menyebabkan tekanan menjadi $-2,89 \mathrm{~m}$. Permasalahan ini dapat diatasi dengan parallel pipa diameter $200 \mathrm{~mm}$ sepanjang $9 \mathrm{~km}$. Parallel pipa tersebut mengakibatkan tekanan pada titik tapping pertama IKK Cawas menjadi 34,65 m dan titik tapping terjauh (blok 19) sebesar $16,34 \mathrm{~m}$. Hasil analisis hidrolika, seperti unit headloss berada pada rentang $(0-5,78) \mathrm{m} / \mathrm{km}$, namun kecepatan masih ada yang di bawah $0,3 \mathrm{~m} /$ detik. Rencana anggaran biaya (RAB) yang dibutuhkan untuk melakukan pengembangan jaringan sebesar $R p$ 2.470.153,051.71.
\end{abstract}

Kata Kunci-Cabang Timur PDAM Kabupaten Klaten, Jaringan Distribusi, EPANET 2.0

\section{PENDAHULUAN}

$U^{2}$ nit Cabang Timur merupakan salah satu unit pelayanan PDAM Kabupaten Klaten dan dibagi menjadi 3 Unit Pelayanan IKK. Persen pelayanan pada tahun 2015 masih rendah, yaitu Unit IKK Ceper 17,6\%; Unit IKK Pedan 2,43\%; dan Unit IKK Cawas 31,26\% [1]. Peningkatan persen pelayanan menjadi hal yang harus dilakukan mengingat pentingnya pemenuhan kebutuhan air untuk masyarakat. Hal ini didukung dengan adanya penambahan debit produksi air sebesar 50 liter/detik. Kondisi eksisting jaringan perlu diketahui sebagai pertimbangan perencanaan pengembangan. Selain itu jaringan distribusi Unit Cabang Timur masih belum berbentuk sistem zonasi sehingga menyulitkan pihak PDAM untuk mengontrol kehilangan air.

\section{METODE PERENCANAAN}

Metode perencanaan ditampilkan pada Gambar 1 dibawah ini.

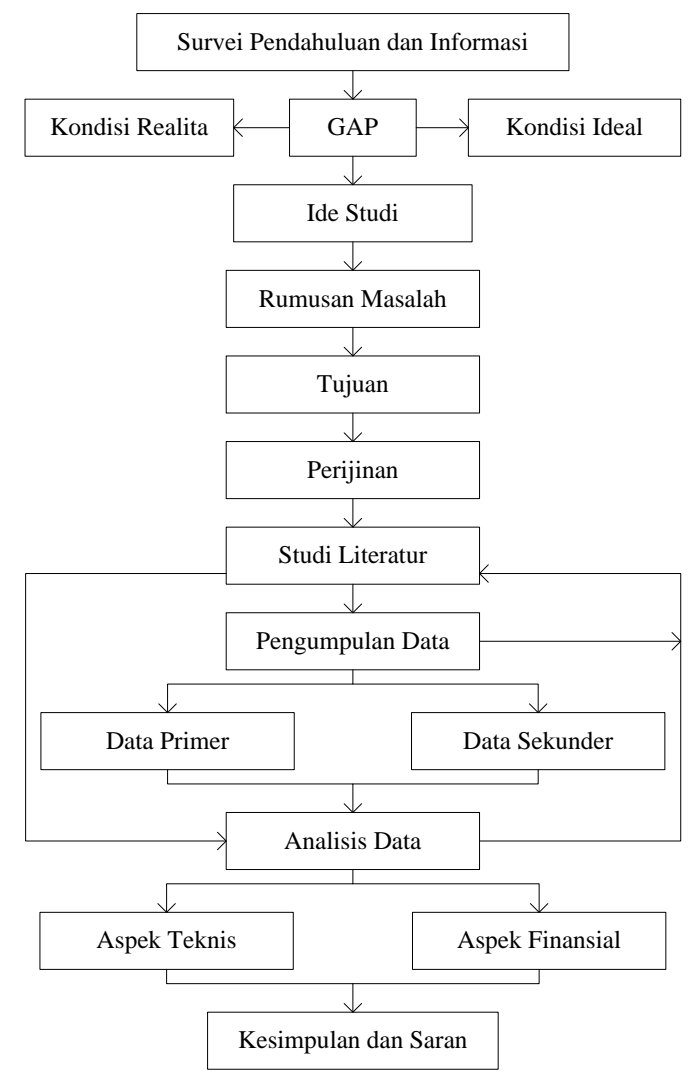

Gambar. 1. Metode Perencanaan

Berikut ini merupakan penjelasan dari metode perencanaan:

A. Survei Pendahuluan dan Informasi

Tahap ini merupakan pengamatan di PDAM Kabupaten 
Klaten untuk mendapatkan gambaran dan informasi sehingga diketahui permasalahan yang ada.

\section{B. Ide Studi}

Berdasarkan pengamatan yang sudah dilakukan, didapatkan ide studi yaitu "Analisis dan Rencana Pengembangan Jaringan Distribusi Air Bersih Unit Cabang Timur PDAM Kabupaten Klaten".

\section{Rumusan Masalah}

Rumusan masalah didapatkan dari permasalahan kondisi realita di Unit Cabang Timur.

\section{Tujuan}

Tujuan dibuat untuk menjawab rumusan masalah.

\section{E. Studi Literatur}

Studi literatur dilakukan dengan mengumpulkan dan mempelajari materi yang mendukung dalam pelaksanaan tugas akhir ini berupa pustaka. Materi yang dipelajari dalam studi literatur ini antara lain sistem jaringan distribusi, bentuk jaringan distribusi, sistem distribusi air minum, pembagian blok pelayanan, pipa dan elemennya, proyeksi penduduk dan fasilitas, kebutuhan air dan fluktuasinya, hidrolika perpipaan, Quantum Geographic Information System (QGIS), dan Epanet 2.0.

\section{F. Perijinan}

Perijinan dilakukan di PDAM Kabupaten Klaten untuk mendapatkan data PDAM, Bappeda Kabupaten Klaten untuk mendapatkan peta daerah perencanaan, dan Dinas Pekerjaaan Umum untuk mendapatkan standar harga.

\section{G. Pengumpulan Data}

Pengumpulan data dibedakan menjadi 2 , yaitu data primer (pengambilan data di lapangan) dan data sekunder berasal dari instansi terkait. Data diambil untuk mengetahui informasi masing-masing Unit IKK. Data primer yang diambil adalah konsumsi pelanggan per orang per hari. Sedangkan data sekunder yang diambil yaitu peta administrasi, peta jaringan distribusi beserta diameter pipa, panjang pipa distribusi, elevasi titik tapping, konsumsi air non domestik, jumlah penduduk terlayani, wilayah pelayanan, pertumbuhan pelanggan, jumlah penduduk dan fasilitas umum, pertumbuhan pelanggan tiap Unit IKK, kehilangan air, dan debit produksi air bersih.

\section{H. Analisis Data}

Analisis data dibagi menjadi dua aspek, yaitu:

1) Aspek teknis

- Pembuatan model sistem jaringan induk dilakukan di software QGIS

- Pembentukan blok pelayanan

Pembentukan blok pelayanan merupakan salah satu upaya untuk mengontrol kehilangan air. Pembentukan blok pelayanan dilakukan di QGIS.

- Analisis jaringan distribusi eksisting menggunakan EPANET 2.0
Model sistem jaringan induk yang sudah dibuat di QGIS dimasukkan ke EPANET 2.0 untuk diraster. Kemudian memasukkan data-data yang dibutuhkan seperti panjang pipa, elevasi tiap node, debit tiap tapping, koefisien kekasaran pipa, serta faktor jam puncak. Hasil analisis berupa kondisi hidrolika perpipaan, seperti kecepatan pipa dan tekanan tiap node digunakan sebagai dasar rencana pengembangan jaringan.

- Analisis rencana pengembangan

Periode perencanaan selama 10 tahun (2016-2026) dibagi menjadi 2 tahap, dimana tahap 1 meningkatkan persen pelayanan dan tahap 2 ditambah dengan daerah pelayanan. Pada analisis ini dihitung proyeksi penduduk, proyeksi fasilitas, proyeksi kebutuhan air, dan pembagian debit tiap blok. Kemudian dilakukan analisis menggunakan EPANET 2.0. Jika hasil analisis belum memenuhi kriteria yang ada, maka jaringan pipa dimodifikasi sedemikian rupa sehingga dapat memenuhi kriteria yang ada.

2) Aspek Finansial

Analisis finansial menghitung bill of quantity (BOQ) dan rencana anggaran biaya (RAB) sesuai standar harga daerah perencanaan.

\section{Kesimpulan dan Saran}

Kesimpulan didapatkan dari hasil analisis data dan harus menjawab tujuan. Sedangkan saran dibuat agar memudahkan penyususnan perencanaan kedepan.

\section{HASIL DAN PEMBAHASAN}

\section{A. Analisis Kondisi Eksisting Jaringan Distribusi}

Unit Cabang Timur dibagi menjadi 3 unit pelayanan untuk melayani 4 kecamatan, yaitu Kecamatan Ceper, Kecamatan Pedan, Kecamatan Cawas, dan Kecamatan Trucuk. Sumber air berasal dari Mata Air Nila dengan debit 64,3 liter/detik dan sumur bor Ponggok 50 liter/detik. Sehingga debit total sebesar 114,3 liter/detik. Unit Cabang Timur melayani pelanggan domestik 6788 sambungan dan non domestik sebanyak 227 sambungan dengan sistem pengaliran gravitasi [2].

- Jaringan Induk dan Blok Pelayanan

Analisis kondisi eksisting dimulai dengan membenahi sistem jaringan distribusi dengan cara membentuk jaringan induk kemudian membuat blok pelayanan sesuai jaringan induk (Gambar 2). Tappingan dari reservoir sebelah kiri merupakan pipa distribusi untuk IKK Ceper dan IKK Pedan, sedangkan sebelah kanan untuk IKK Cawas. Blok pelayanan yang dibentuk sebanyak 26 blok dan 5 tapping. Hal ini untuk memudahkan pembagian debit untuk analisis dan mengontrol kehilangan air saat diaplikasikan dilapangan. Unit IKK Ceper dan IKK Pedan dibagi menjadi 9 blok pelayanan, sedangkan IKK Cawas menjadi 20 blok dan 4 titik tapping (Tabel 2). Analisis dengan program EPANET 2.0 membutuhkan input data seperti debit tiap tapping pipa, terdiri dari data pemakaian air domestik dan non domestik yang didapatkan dari perhitungan, panjang pipa dan diameter pipa dari sistem informasi geografis, elevasi tiap node dari Google Earth, 
dan koefisien kekasaran pipa (c) tergantung jenis pipa yang digunakan. Pipa yang digunakan adalah jenis PVC, sehinga nilai $\mathrm{c}$ adalah 150 [3].

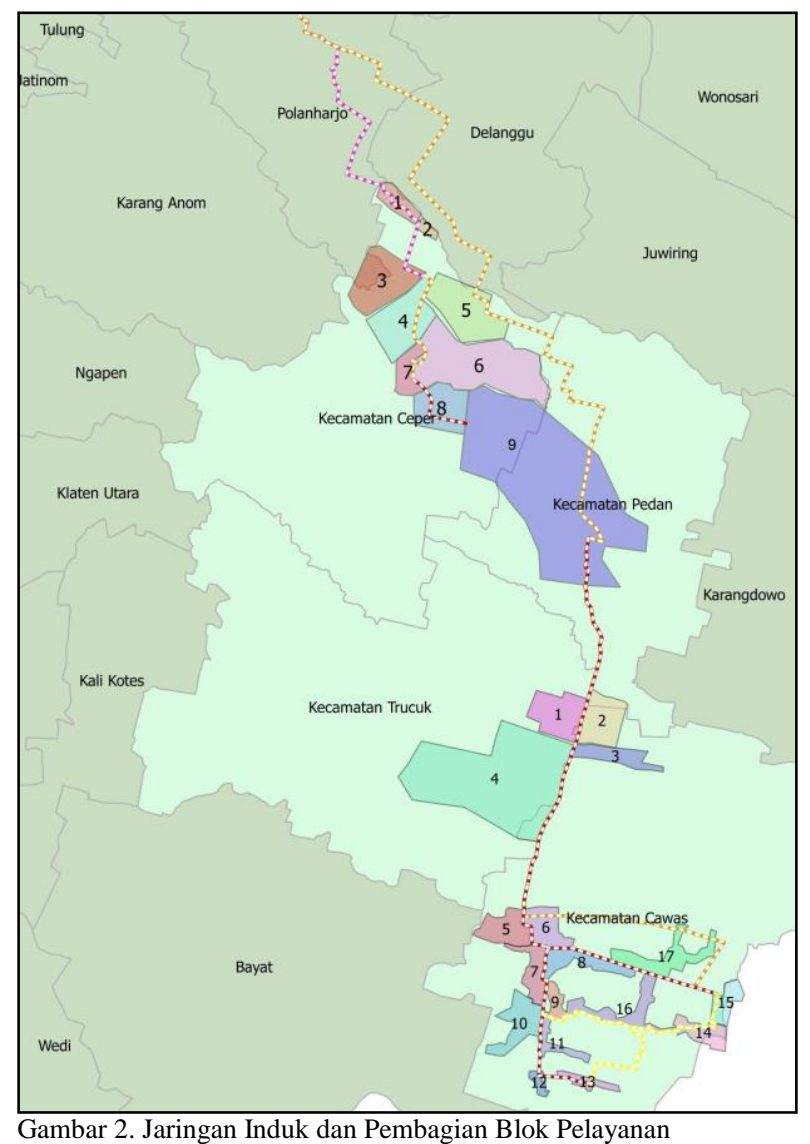

- Pemakaian Air Domestik dan Non Domestik

Pemakaian air domestik didapatkan dari pengamatan penggunaan air domestik 10 sambungan rumah (SR) dengan pelayanan kontinyu (24 jam). Berdasarkan hasil pengamatan tersebut, rata - rata pemakaian air sebesar 101,17 liter/orang.hari dan dibulatkan menjadi 100 liter/orang.hari. Sedangkan pemakaian air non domestik didapatkan dari pembacaan meter air oleh PDAM pada Bulan Maret 2016 yang ditunjukkan pada Tabel 1.

Tabel 1.

Pemakaian Air Non Domestik

\begin{tabular}{lr}
\hline \multicolumn{1}{c}{ Jenis Fasilitas } & Debit (Liter/hari) \\
\hline Industri & 2064,20 \\
RS & 300,00 \\
Puskesmas & 1900,00 \\
Sekolah & 1013,64 \\
Niaga & 300,00 \\
Tempat ibadah & 906,57 \\
Kantor & 363,33 \\
\hline \hline
\end{tabular}

- Pembagian Debit tiap Blok

Menurut Badan Pusat Statistik tahun 2013, rata - rata anggota rumah tangga keempat kecamatan tersebut adalah 4 orang. Data tersebut digunakan untuk menghitung jumlah pemakaian air dalam 1 SR dengan cara mengkalikan dengan pemakaian air per orang per hari.
Pembagian debit tiap blok dapat dilihat pada Tabel 2. Tabel 2.

Debit Tiap Blok Pelayanan

\begin{tabular}{cccc}
\hline \hline No & Unit Pelayanan IKK & Blok & Debit \\
\hline 1 & & J-2 & 0,003 \\
2 & & J-5 & 0,041 \\
3 & & Blok 1 & 2,607 \\
4 & & Blok 2 & 0,972 \\
5 & & Blok 3 & 0,505 \\
6 & & Blok 4 & 0,971 \\
7 & & J-6 & 0,619 \\
8 & & Blok 5 & 1,632 \\
9 & & Blok 6 & 1,742 \\
10 & & Blok 7 & 0,679 \\
11 & & Blok 8 & 1,103 \\
12 & Cawas & Blok 9 & 1,142 \\
13 & & Blok & 1,209 \\
14 & & Blok & 0,549 \\
15 & & Blok & 0,256 \\
16 & & Biôk & 0,079 \\
17 & & J-13 & 0,131 \\
18 & & J-15 & 0,438 \\
19 & & Blok & 0,822 \\
20 & & Blok & 0,502 \\
21 & & Blok & 1,513 \\
22 & & Blokk & 1,589 \\
& & -- & 19,103 \\
1 & Sub jumlah & Blok 1 & 0,989 \\
2 & & Blok 2 & 0,433 \\
3 & & Blok 3 & 1,272 \\
4 & & Blok 4 & 1,823 \\
5 & Ceper dan Pedan & Blok 5 & 3,528 \\
6 & & Blok 6 & 3,172 \\
7 & & Blok 7 & 0,987 \\
8 & & Blok 8 & 1,632 \\
9 & & Blok 9 & 1,425 \\
& & & 15,261 \\
& & 34,364 \\
\hline \hline
\end{tabular}

- Analisis jaringan eksisting menggunakan EPANET 2.0

Sistem jaringan dan blok pelayanan yang telah dibuat sebelumnya, dimasukkan kedalam program EPANET 2.0 untuk diraster dan dimasukkan data berupa debit tiap blok, panjang pipa, elevasi tiap node, diameter pipa, dan koefisien kekasaran pipa. Kemudian dilakukan analisis menggunakan EPANET 2.0 untuk mengetahui kondisi hidrolika dan dibandingkan dengan kriteria. Sisa tekan yang diperbolehkan mempunyai rentang antara $(10-70) \mathrm{m}$ [4], sedangkan kecepatan pipa PVC antara $(0,3-3)$ $\mathrm{m} /$ detik [5]. Hasil analisis kondisi eksisting (Gambar 3) menunjukkan bahwa hidrolika pipa berupa tekanan dan unit headloss memenuhi kriteria, yaitu untuk tekanan antara $(15,43-59,99) \mathrm{m}$ dan unit headloss $(0-3,51) \mathrm{m} / \mathrm{km}$. Akan tetapi kecepatan air dalam pipa beberapa masih berada di bawah $0,3 \mathrm{~m} /$ detik. Kecepatan aliran air berkisar antara $(0-$ $0,91) \mathrm{m} /$ detik. 


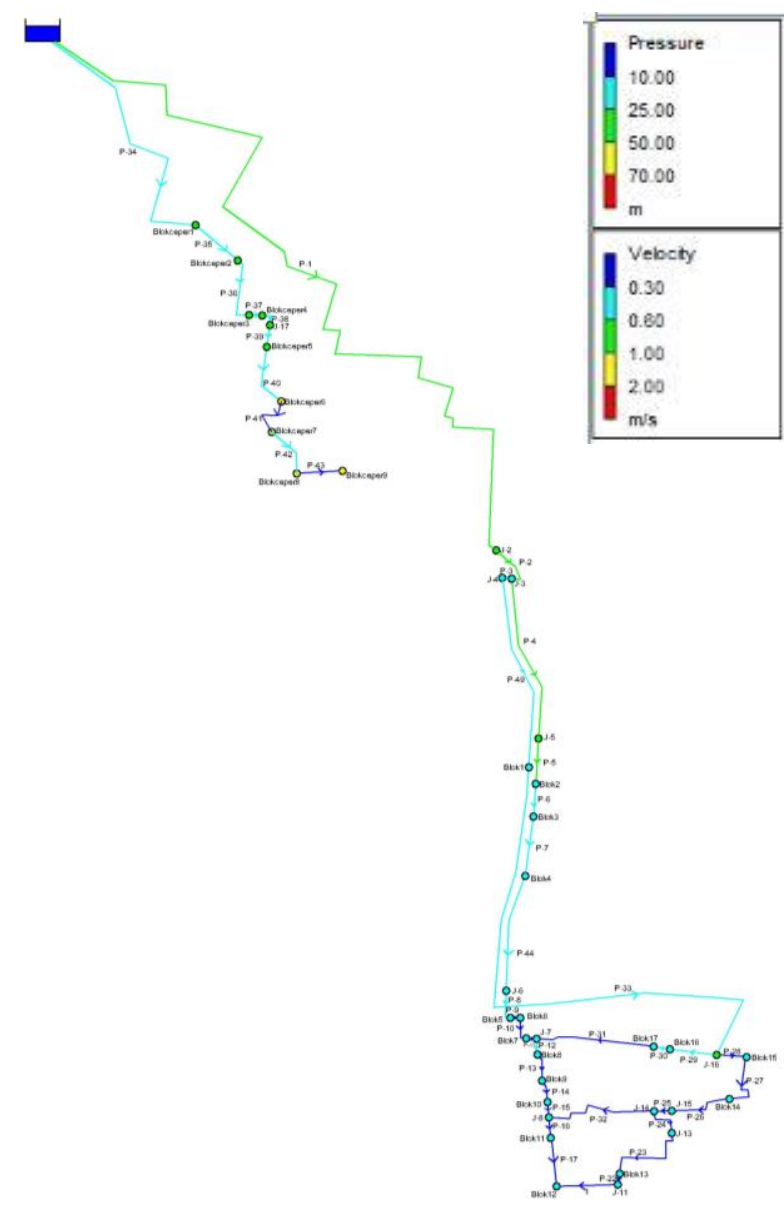

Gambar 3. Hasil Analisis Kondisi Eksisting Jaringan Menggunakan EPANET 2.0.

\section{B. Rencana Pengembangan Jaringan Distribusi}

Merencanakan pengembangan jaringan perlu diketahui persen pelayanan eksisting yang digunakan sebagai data awal peningkatan persen pelayanan. Selain itu diperlukan proyeksi penduduk, proyeksi fasilitas, dan proyeksi kebutuhan air sehingga diketahui debit total yang harus tersedia di PDAM untuk melayani masyarakat.

- Proyeksi penduduk

Proyeksi penduduk digunakan untuk menghitung proyeksi kebutuhan air domestik. Proyeksi penduduk dapat dihitung menggunakan metode aritmatik, metode least square, atau metode geometrik. Metode yang dipilih merupakan metode dengan nilai koefisien korelasi (r) mendekati 1 . Metode terpilih untuk menghitung proyeksi penduduk adalah metode geometrik dengan rumus sebagai berikut.

$\mathrm{Pn}=$ Po $x(1+\mathrm{r})^{\mathrm{dn} .}$

Dimana :

Pn = Jumlah penduduk tahun $\mathrm{n}$

Po = Jumlah penduduk tahun dasar

$\mathrm{r} \quad=$ rata-rata pertambahan penduduk pertahun

$\mathrm{dn}=$ periode waktu dalam tahun

- Proyeksi Fasilitas

Proyeksi fasilitas digunakan untuk memproyeksikan kebutuhan air non domestik, dengan rumus sebagai berikut.
$\mathrm{Fn}=\mathrm{Pn} / \mathrm{Po} \times \mathrm{Fo}$

Dimana:

$\mathrm{Fn}=$ jumlah fasilitas umum pada tahun akhir proyeksi

$\mathrm{Pn}=$ Jumlah penduduk di akhir proyeksi

Fo $=$ Jumlah fasilitas umum pada awal proyeksi

Po $=$ Jumlah penduduk di awal proyeksi

- Proyeksi Kebutuhan Air

Peningkatan persen pelayanan dilihat dari tren pertumbuhan pelanggan di masing-masing unit. Unit IKK Ceper direncanakan meningkat sebesar $0,8 \%$ pada tahap 1 dan menjadi $1 \%$ pada tahap 2 karena daerah tersebut merupakan sentra industri logam [6]; Unit IKK Pedan 0,5\%; dan Unit IKK Cawas 2\%. Daerah pelayanan baru terletak di Unit IKK Cawas dan direncanakan persen pelayanan awal sebesar 20\% dengan peningkatan sebesar $2 \%$ tiap tahunnya. Kehilangan air di Unit IKK Ceper sebesar $26,2 \%$ dan direncanakan turun $0,7 \%$ tiap tahunnya agar tingkat kehilangan air memenuhi standar sebesar $20 \%$ [7]. Hal tersebut dapat dilakukan dengan cara menghitung selisih antara air yang terbaca di tiap meter air dengan yang tercatat di rekening air kemudian dilakukan telusur pipa di blok pelayanan yang mengalami kehilangan air. Sedangkan 2 Unit IKK lainnya tidak dilakukan pengurangan kehilangan air karena sudah memenuhi kriteria. Akan tetapi kontrol kehilangan air tetap dilakukan dengan menghitung selisih air yang terdistribusi dan yang terbaca di rekening. Total debit yang harus tersedia di PDAM Kabupaten Klaten pada tahun 2026 sebesar 63 liter/detik. Debit eksisting air produksi Unit Cabang Timur masih memenuhi untuk mensuplai kebutuhan air sampai tahun 2026.

- Pembagian Debit tiap Blok Pelayanan

Terjadi penambahan 3 blok pelayanan pada tahap 2, yaitu blok 18, 19, dan 20 (Gambar 4), sehingga blok pelayanan menjadi sebanyak 29 blok dan 5 tapping. Tabel 3 berikut adalah pembagian debit tiap blok pelayanan setelah pengembangan.

Tabel 3.

Pembagian Debit tiap Blok Pelayanan

\begin{tabular}{cccc}
\hline \hline No & Unit Pelayanan IKK & \multicolumn{1}{c}{ Blok } & Debit \\
1 & J-2 & 0,008 \\
2 & & J-5 & 0,508 \\
3 & Cawas & Blok 1 & 3,897 \\
4 & Blok 2 & 1,733 \\
5 & Blok 3 & 0,743 \\
6 & & Blok 4 & 5,089 \\
7 & J-6 & 1,232 \\
8 & Blok 5 & 2,635 \\
9 & Blok 6 & 2,624 \\
10 & Blok 7 & 0,970 \\
11 & Blok 8 & 1,663 \\
12 & Blok 9 & 1,690 \\
13 & Cawas & Blok 10 & 2,078 \\
14 & & Blok 11 & 0,861 \\
15 & & Blok 12 & 0,792 \\
16 & & Blok 13 & 0,245 \\
\hline \hline
\end{tabular}




\begin{tabular}{|c|c|c|c|}
\hline 17 & & $\mathrm{~J}-13$ & 0,360 \\
\hline 18 & & $\mathrm{~J}-15$ & 0,611 \\
\hline 19 & & Blok 17 & 2,404 \\
\hline 20 & & Blok 14 & 1,219 \\
\hline 21 & & Blok 15 & 0,813 \\
\hline 22 & & Blok 16 & 3,207 \\
\hline 23 & & Blok 18 & 0,720 \\
\hline 24 & & Blok 19 & 0,360 \\
\hline 25 & & Blok 20 & 1,394 \\
\hline \multicolumn{3}{|c|}{ Sub jumlah } & 37,9 \\
\hline 1 & Ceper dan Pedan & Blok 1 & 1,428 \\
\hline 2 & & Blok 2 & 0,612 \\
\hline 3 & & Blok 3 & 1,428 \\
\hline 4 & & Blok 4 & 3,565 \\
\hline 5 & & Blok 5 & 4,818 \\
\hline 6 & & Blok 6 & 4,709 \\
\hline 7 & & Blok 7 & 1,811 \\
\hline 8 & & Blok 8 & 3,089 \\
\hline 9 & & Blok 9 & 3,683 \\
\hline \multicolumn{3}{|c|}{ Sub jumlah } & 25,1 \\
\hline \multicolumn{3}{|c|}{ Jumlah } & 63,0 \\
\hline
\end{tabular}

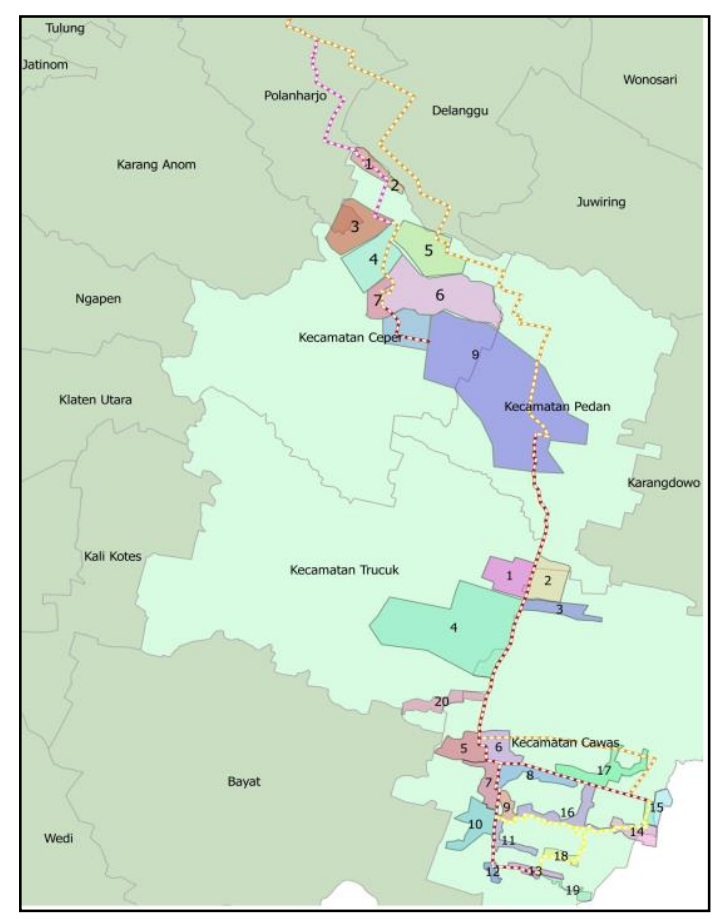

- Perhitungan Diameter Pipa Blok Pelayanan Baru

Diameter pipa dihitung dengan mengasumsikan kecepatan pada pipa dan dihitung menggunakan rumus sebagai berikut.

$\mathrm{Q}=\mathrm{v} \times \mathrm{A}$.

$\mathrm{A}=0,25 \times \pi \times \mathrm{D}^{2}$.

Dimana: $\mathrm{Q}=$ debit air $\left(\mathrm{m}^{3} /\right.$ detik $)$

$\mathrm{V}=$ kecepatan aliran $(\mathrm{m} /$ detik $)$

$\mathrm{A}=$ luas penampang pipa $\left(\mathrm{m}^{2}\right)$

$\mathrm{D}=$ diameter pipa $(\mathrm{m})$
Berdasarkan perhitungan tersebut, didapatkan diameter pipa untuk blok 18 sebesar $50 \mathrm{~mm}$ dan blok 20 sebesar $75 \mathrm{~mm}$.

- Analisis Pengembangan Jaringan menggunakan EPANET 2.0

Hasil analisis pengembangan jaringan ditunjukkan pada Gambar 5 dibawah ini.
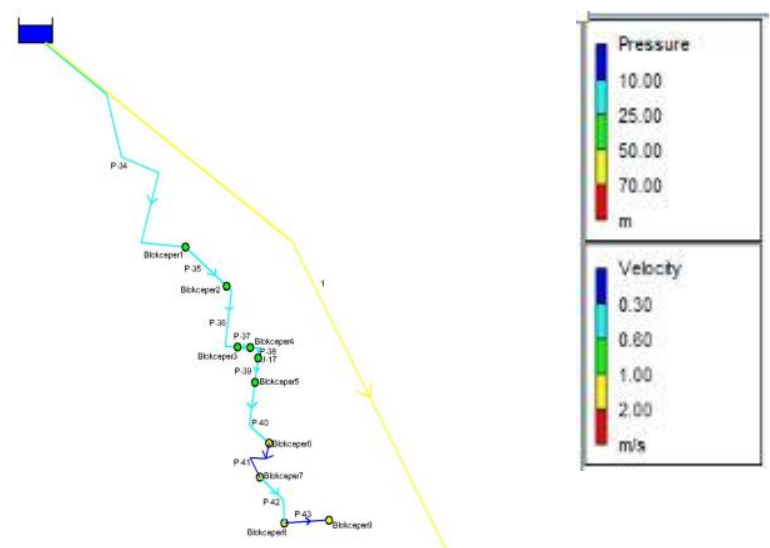

Gambar 5. Hasil Analisis Pengembangan Jaringan

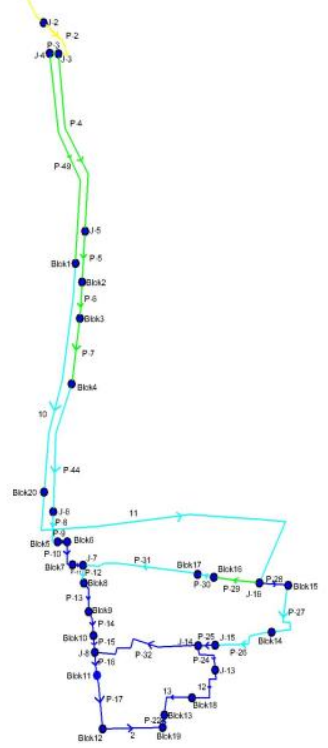

Berdasarkan hasil analisis tersebut, pipa tapping dari reservoir menuju titik tapping pertama pelanggan IKK Cawas (Pipe 1) mempunyai unit headloss $5,78 \mathrm{~m} / \mathrm{km}$ dan panjang pipa $14,35 \mathrm{~km}$. Hal ini menyebabkan headloss yang besar, yaitu $82,942 \mathrm{~m}$ sehingga $\mathrm{m}$ tekanan pada titik tapping pertama (J-2) menjadi -2,89 $\mathrm{m}$ dan titik pelayanan terjauh (blok 19) sebesar $\quad-21,2 \mathrm{~m}$.

- Modifikasi Jaringan Pipa

Permasalahan tekanan negatif pada titik tapping perlu dilakukan penyelesaian. Modifikasi jaringan dilakukan menggunakan bantuan EPANET 2.0. Berdasarkan analisis yang dilakukan, permasalahan tekanan negatif dapat diatasi dengan cara melakukan paralel pipa dengan diameter 200 mm sepanjang $9 \mathrm{~km}$ yang ditunjukkan dengan kode Pipe 7 (Gambar 6). Paralel pipa tersebut mengakibatkan tekanan pada titik tapping pertama IKK Cawas (J-2) menjadi 34,65 
m dan titik tapping terjauh (blok 19) sebesar 16,34 m. Hasil analisis hidrolika, seperti unit headloss berada pada rentang $(0-5,78) \mathrm{m} / \mathrm{km}$, namun kecepatan masih ada yang di bawah $0,3 \mathrm{~m} /$ detik.

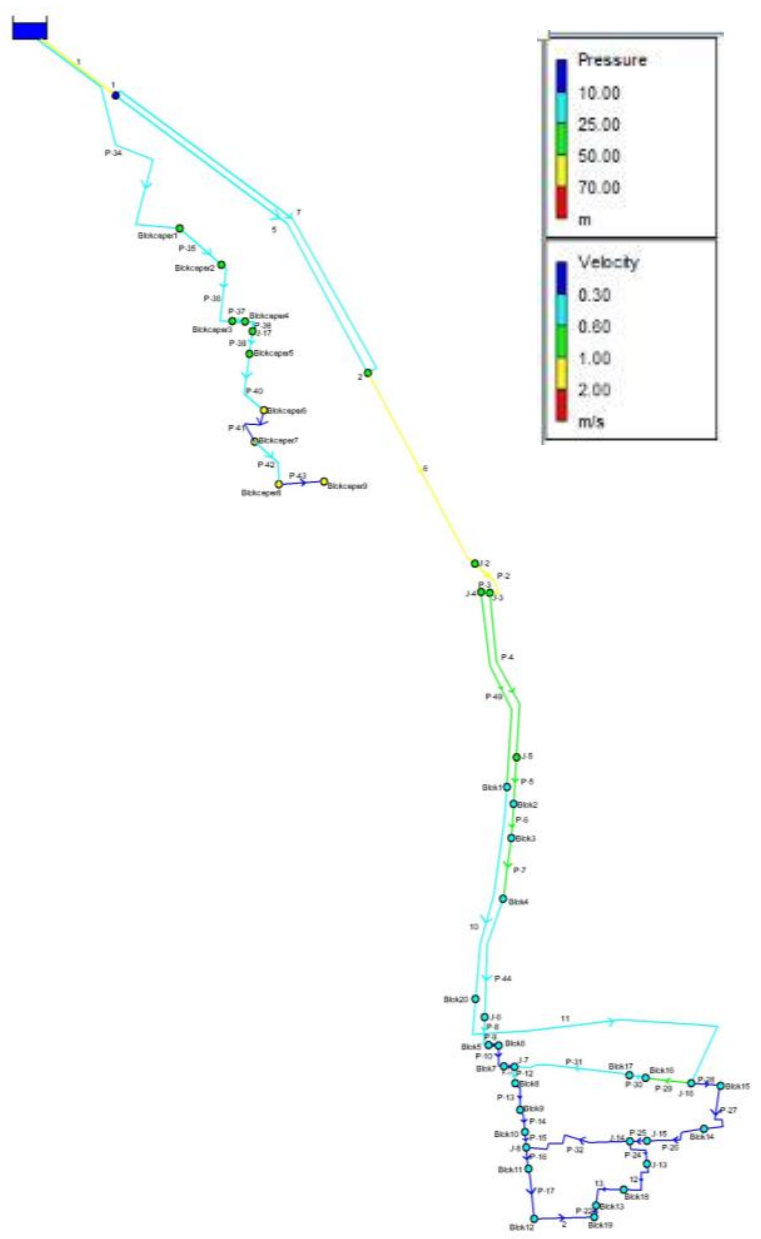

Gambar 6. Hasil Analisis Modifikasi Pipa Jaringan Distribusi

\section{Rencana Anggaran Biaya (RAB)}

Perhitungan RAB dibagi menjadi beberapa item pekerjaan (Tabel 4). Total biaya yang dikeluarkan untuk realisasi perencanaan sebesar Rp Rp2.470.153.015,71.

Tabel 4.

Rencana Anggaran Biaya

\begin{tabular}{cccr}
\hline \hline No & Item Pekerjaan & \multicolumn{1}{c}{ Biaya } \\
\hline 1 & Penanaman pipa dan aksesoris & $\mathrm{Rp}$ & $2.238 .757 .631,28$ \\
2 & Pekerjaan thrust block & $\mathrm{Rp}$ & $3.494 .954,43$ \\
3 & Pekerjaan detail junction & $\mathrm{Rp}$ & $227.900 .430,00$ \\
& Total & $\mathrm{Rp}$ & $2.470 .153 .015,71$ \\
\hline \hline
\end{tabular}

\section{KESIMPULAN/RINGKASAN}

A. Untuk mengontrol kehilangan air, Unit Cabang Timur dibagi 26 blok pelayanan dan 5 tapping untuk eksisting. Sedangkan setelah dilakukan pengembangan menjadi 29 blok dan 5 tapping.

B. Kondisi hidrolika jaringan distribusi air bersih eksisting Unit Pelayanan Cabang Timur memenuhi kriteria untuk tekanan dan headloss, sedangkan kecepatan pipa masih ada yang berada dibawah $0,3 \mathrm{~m} /$ detik. Hal ini memungkinkan untuk dilakukan pengembangan jaringan.

C. (1) Persen pelayanan pada tahun 2026 masing - masing unit Pelayanan IKK adalah sebagai berikut:

- Ceper $=20,7 \%$

- Pedan $=6,7 \%$

- Cawas $=54,7 \%$

(2) Tapping dari reservoir sampai tapping pertama pelanggan IKK Cawas menunjukkan tekanan negatif karena headloss tinggi. Setelah dilakukan modifikasi berupa paralel pipa berdiameter $200 \mathrm{~mm}$ sepanjang $9 \mathrm{~km}$, kondisi hidrolika memenuhi kriteria, kecuali kecepatan pipa masih ada yang berada dibawah $0,3 \mathrm{~m} /$ detik.

\section{UCAPAN TERIMA KASIH}

Penulis mengucapkan terimakasih kepada Jurusan Teknik Lingkungan, PDAM Kabupaten Klaten, Bappeda Kabupaten Klaten, Badan Pusat Statistik Kabupaten Klaten, dan Dinas Pekerjaan Umum Kabupaten Klaten yang telah membantu penulis dalam meyelesaikan penyusunan perencanaan.

\section{DAFTAR PUSTAKA}

[1] PDAM Kabupaten Klaten. 2015. Laporan Bulan November 2015 Unit Cabang Timur. Klaten: PDAM Kabupaten Klaten.

[2] PDAM Kabupaten Klaten. 2016. Laporan Bulan Januari 2016 Unit Cabang Timur. Klaten: PDAM Kabupaten Klaten.

[3] Ram S, Gupta. 1989. Hydrology and Hidraulic System. London: Prentice Hall.

[4] Trijoko, 2010. Unit Air Baku dalam Sistem Penyediaan Air Bersih. Bandung: Graha Ilmu.

[5] Kementerian Pekerjaan Umum. 2007. Peraturan Menteri Pekerjaan Umum No 18 Tahun 2007 tentang Penyelenggaraan Pengembangan Sistem penyediaan Air Minum. Jakarta: Kementrian PU.

[6] Badan Pusat Statistik Kabupaten Klaten. 2013. Statistik Industri Besar dan Sedang Tahun 2013. Klaten: BPS Kabupaten Klaten.

[7] Mangkoedihardjo S. dan Samudro, G. 2012. Evaluasi dan Perencanaan Kebutuhan Air Minum. Surabaya: Guna Widya. 